\title{
A comunicação no ensino de Ciências: reflexões a partir de uma revisão bibliográfica
}

\section{no contexto brasileiro}

\author{
Communication in Science teaching: reflections from a bibliographic review in the Brazilian \\ context
}
La comunicación en la enseñanza de las Ciencias: reflexiones de una revisión de la literatura en el contexto brasileño

\author{
Eloisa Assunção de Melo Lopes \\ ORCID: https://orcid.org/0000-0003-3058-2761 \\ Universidade Federal de Jataí, Brasil \\ E-mail: eloisalopes@ufj.edu.br \\ Marcelo Ximenes Aguiar Bizerril \\ ORCID: https://orcid.org/0000-0002-2993-155X \\ Universidade de Brasília, Brasil \\ E-mail: bizerril@unb.br
}

\begin{abstract}
Resumo
A mudança em curso relativa à intensificação do uso dos meios de comunicação pela sociedade e as formas de acesso e rapidez com que as informações circulam têm influenciado, de maneira significativa, os processos de ensino e aprendizagem que ocorrem dentro e fora da escola. Assim sendo, o objetivo dessa pesquisa foi analisar como a área de ensino de Ciências da Natureza tem se apropriado dos diferentes meios e recursos de comunicação no contexto brasileiro. Para tal, foram escolhidos cinco periódicos nacionais da área, nos quais foram selecionados 116 artigos no período entre 2010 a 2016. Para análise dos dados foram construídas categorias, por meio da Análise Textual Discursiva. Foram identificados trabalhos descritivos, trabalhos com aplicação prática no ensino, mas com pouco envolvimento dos estudantes, e trabalhos com uma perspectiva mais democrática de participação e protagonismo. A comunicação esteve presente em todos os processos educativos descritos. Prevaleceu o uso de recursos digitais, tendência que merece ser acompanhada com atenção, observando a necessidade dos educadores organizarem e planejarem processos de ensino e aprendizagem de forma ousada e criativa, na busca pelo protagonismo dos estudantes e da reflexão sobre o uso dos recursos que devem vir acompanhados de leitura crítica e problematização.

Palavras-chave: Interface educação-comunicação; Recursos digitais; Leitura crítica.
\end{abstract}

\begin{abstract}
The ongoing change regarding the intensification of the use of media by society and the forms of access and speed with which information flows, have significantly influenced the teaching and learning processes that take place inside and outside the school. Therefore, the objective of this research was to analyze how the Nature Science teaching area has been dealing with the different means and resources of communication in the Brazilian context. To this end, five national journals in the area were chosen, from which 116 articles were selected in the period between 2010 and 2016. For data analysis, categories were constructed using Discursive Textual Analysis. There were identified descriptive works, works with practical application in teaching, but with little student involvement, and works with a more democratic perspective of participation and protagonism. Communication was present in all described educational processes. The use of digital resources prevailed, a trend that deserves to be closely monitored, noting the need for educators to organize and plan teaching and learning processes in a bold and creative way, in the search for the protagonism of students and the thought on the use of resources which must be carried out with critical reading and questioning.
\end{abstract}

Keywords: Education-communication interface; Digital resources; Critical reading.

\section{Resumen}

El cambio continuo en cuanto a la intensificación del uso de los medios de comunicación por parte de la sociedad y las formas de acceso y velocidad con la que circula la información, han influido significativamente en los procesos de enseñanza y aprendizaje que se desarrollan dentro y fuera de la escuela. Por tanto, el objetivo de esta investigación fue analizar cómo el área de enseñanza de las Ciencias de la Naturaleza se ha apropiado de los diferentes medios y recursos de comunicación en el contexto brasileño. Para ello, se eligieron cinco revistas nacionales del área, de las cuales se seleccionaron 116 artículos en el período comprendido entre 2010 y 2016. Para el análisis de datos se 
construyeron categorías mediante Análisis Textual Discursivo. Se identificaron trabajos descriptivos, trabajos con aplicación práctica en la docencia, pero con escasa participación de los estudiantes, y trabajos con una perspectiva más democrática de participación y protagonismo. La comunicación estuvo presente en todos los procesos educativos descritos. Se impuso el uso de recursos digitales, tendencia que merece ser monitoreada de cerca, señalando la necesidad de que los educadores organicen y planifiquen los procesos de enseñanza y aprendizaje de manera audaz y creativa, en la búsqueda del protagonismo de los estudiantes y la reflexión sobre la uso de recursos que debe ir acompañado de lectura crítica y cuestionamiento.

Palabras clave: Interfaz educación-comunicación; Recursos digitales; Lectura critica.

\section{Introdução}

O processo histórico-social constituinte de nossas sociedades cria um cenário múltiplo em que prefiguram novas possibilidades de comunicação e novas formas de relação, configurando o que Belloni (2009, p.12) denomina de "nova paisagem comunicacional e informacional”.

São relações que se estabelecem em um cenário que Citelli e Costa $(2011$, p.7) descrevem como de "crescente aceleração tecnológica, de reordenações sociais, culturais, filosóficas, das passagens históricas” o que, de acordo com eles, leva o mundo da educação a redefinir projetos, procedimentos e objetivos.

Nesse cenário, os lugares e espaços educativos estão permeados por diversos e diferentes modos de agir, mediados por formas de comunicação, decorrentes não só da relação com as tecnologias e os meios de comunicação (mídias), mas também com as implicações político-sociais geradas a partir das articulações presentes nas relações socioculturais em uma sociedade diversa.

Educar nesse contexto implica ações em nível inter e transdisciplinar que proporcionem pensar os processos comunicativos de forma ampla.

Já não estamos somente frente a um "fato tecnológico" ou à dominação de uma lógica comercial, mas sim diante de mudanças profundas em todas as práticas culturais de memória, de saber, de imaginário e de criação, que nos introduzem em uma mutação da sensibilidade. (Martín-Barbero, 2014, p. 64)

Formas de expressão digitais e virtuais em grande escala são vivenciadas. Inúmeros sites e softwares como o aplicativo WhatsApp®, as mídias sociais Facebook®, Instagram ${ }^{\circledR}$ e Twitter@ são resultado de um mundo capitalista na busca por inovações e formas de expressão que atendam a necessidade humana de comunicar. São canais de comunicação que convivem com meios tradicionais como rádio e televisão e que têm permitido, na última década, que muitas pessoas se expressem, interajam e comuniquem de maneira dinâmica e rápida.

Rapidez e imediatismo definem a virtualidade dessas formas de comunicação e, no que diz respeito às Ciências da Natureza, inúmeros sites divulgam e trazem informações sobre o assunto. Um bom exemplo é o site YouTube.com® fundado em 2005 que, caracterizado por ser uma plataforma de compartilhamento, reúne muitos vídeos e canais relacionados aos mais diversos temas da área permitindo que o público que possui acesso à internet, possa, de maneira dinâmica, visualizar, compartilhar e até mesmo produzir informações.

Nesse cenário, os níveis de interação são muitos e o acesso não pode ser generalizado, porém deve ser compreendido como algo cada vez mais democrático. Os recursos digitais/informáticos hoje podem causar fascínio, dependência e excesso de informações provocando ruídos nas formas de comunicação possibilitadas a seus usuários, e é nesse contexto que surgem ou se reafirmam definições como Cyberbullying (Souza et al, 2014; Simão et al, 2017); Fake News (Teixeira, 2018; Monari et al, 2019) e Pós-Verdade (Oliveira, 2018; Adorno et al, 2018), as duas últimas muito relacionadas à popularização da internet e a disseminação da informação em grande escala.

Discursos em disputa, manipulação por interesses econômicos, linguagem alarmista, e falta de evidências científicas 
têm ameaçado a qualidade da informação científica. Notícias falsas em diversas áreas, como o emblemático caso das vacinas na saúde (Henriques, 2018; Ribeiro et al, 2018), têm tido implicações sociais com consequências seríssimas.

Ao dimensionarmos a problemática da mídia, das Fake News e das Ciências pode-se refletir sobre uma perigosa indústria, que por sua superficialidade, imediatismo e falta de contraditório, bem como por seu amplo poder de alcance levam a tendenciosas certezas, cuja solidez não abre espaço para a dúvida, tornando-as perigosas, pois quando não há dúvida não há questionamentos, problematização, diálogo e argumentação.

Essa problemática se intensifica com a ausência de processos de ensino e aprendizagem que tratem a comunicação como algo a ser discutido com os estudantes na escola e nos processos de ensino e aprendizagem. Alie-se a isso o cenário político de desvalorização da Ciência em que a infraestrutura e as pesquisas realizadas em Universidades e outras instituições públicas relacionadas ao ensino se encontram ameaçadas pelo próprio governo que as sustentam (Leher, 2019), em meio a um nebuloso universo de informações confusamente justificadas.

Essas situações reafirmam a necessidade de atenção ao caráter educativo da comunicação aliando os meios de comunicação aos processos de ensino e aprendizagem em Ciências. É preciso criar espaços para a dúvida, para a problematização, para a crítica e para a construção de habilidades que permitam discutir a realidade valorizando o ser humano e os seus direitos.

Por isso, educadores e gestores devem estar atentos às diversas possibilidades que se perdem nos hibridismos e nas interconectividades advindas da constituição de uma sociedade plural e dinâmica onde vivem sujeitos denominados de "prosumers"1 (Saad \& Raposo, 2017, p. 126), "YouTubers" (Bernardazzi, 2016, p.1) e outras terminologias advindas da comunicação multimidiática, não deixando de considerá-las nos processos educativos, pois lápis, borracha, lousa, giz, rádio, televisão, computador, internet, mídias sociais, smartphones, tablets, enfim, sujeitos, escola, educação e comunicação convivem.

Isto posto, compreende-se que a comunicação é um eixo estruturante da sociedade contemporânea, logo é desejável que os professores se apropriem do tema para associá-lo a sua prática na perspectiva da formação cidadã.

No contexto da educação em ciências esse fato parece ser ainda mais relevante, dada a forte tendência de diversos campos da pesquisa em ensino de ciências em torná-la mais fortemente associada à realidade, e ao debate crítico sobre o papel da ciência e tecnologia na sociedade (Chassot, 2000; Praia \& Jorge, 2000; Teixeira, 2003; Santos, 2008, 2012; Santos; Mortimer, 2009; Bazzo, 2012), o que não pode excluir o papel da comunicação, cujas diferentes formas e meios, cada vez mais predominantes na sociedade, têm requisitado do Ensino de Ciências processos de ensino e aprendizagem cada vez mais dinâmicos.

Assim sendo, considerando que a comunicação envolve uma complexidade de elementos que se inter-relacionam, sua forte ligação com a educação e com os processos de ensino e aprendizagem em ciências, e que ela não deve ser compreendida como "um mero instrumento midiático e tecnológico, e sim, antes de tudo, como um componente pedagógico" (Kaplún, 1999, p. 68), o objetivo dessa pesquisa foi analisar como a área de ensino de Ciências da Natureza tem se apropriado dos diferentes meios e recursos de comunicação no contexto brasileiro.

\section{Metodologia}

Para a revisão de literatura, foram selecionados cinco periódicos brasileiros da área de Ensino de Ciências, nos quais

\footnotetext{
${ }^{1} \mathrm{O}$ termo prosumer é decorrente da junção dos termos, em inglês, producer (produtor) e consumer (consumidor). Para Saad e Raposo (2017, p. 126) "a dinâmica colaborativa da rede consolida mudanças significativas no comportamento e nos hábitos de consumo e consumidores, fortalecendo uma geração disposta a criar e alterar informação e cultura por meio da diversão e do esforço participativo. Eles não são somente consumidores, mas prosumers, que coinovam e coproduzem o que consomem, compartilhando ideias, dicas e modificações de produtos que julgam relevantes".
} 
buscou-se elementos que permitissem uma compreensão de como a comunicação vem sendo trabalhada na área. A escolha se deu pela relevância das pesquisas na área de Educação em Ciências, pela abrangência nacional e internacional, bem como pela facilidade de acesso online. Além do mais, por serem de livre acesso e gratuitas, possibilitam que todos possam ler, baixar e compartilhar resultados de pesquisa de qualidade. Os nomes das revistas, código International Standard Serial Number (ISSN) das versões online e número de artigos selecionados para análise em cada uma das revistas estão listados na tabela Tabela 1.

Tabela 1 - Informações a respeito das revistas analisadas na revisão.

\begin{tabular}{|c|c|c|}
\hline Revistas & $\begin{array}{c}\text { Código (ISSN) } \\
\text { versão online }\end{array}$ & $\mathbf{N}^{\circ}$ de artigos selecionados \\
\hline $\begin{array}{l}\text { Experiências em Ensino de Ciências. Universidade Federal do Mato Grosso } \\
\text { (UFMT) }\end{array}$ & $1982-2413$ & $32(27,5 \%)$ \\
\hline Ciência \& Educação. Universidade Estadual Paulista (Unesp) & 1980-850X & $30(25,8 \%)$ \\
\hline $\begin{array}{l}\text { Revista Brasileira de Pesquisa em Educação em Ciências. Periódico oficial } \\
\text { da Associação Brasileira de Pesquisa em Educação em Ciências (ABRAPEC). }\end{array}$ & $1984-2686$ & $23(19,8 \%)$ \\
\hline $\begin{array}{l}\text { Ensaio - Pesquisa em Educação em Ciências. Universidade Federal de Minas } \\
\text { Gerais (UFMG). }\end{array}$ & $1983-2117$ & $19(16,3 \%)$ \\
\hline $\begin{array}{l}\text { Investigação em Ensino de Ciências. Universidade Federal do Rio Grande do } \\
\text { Sul (UFRGS). }\end{array}$ & $1518-8795$ & $12(10,3 \%)$ \\
\hline
\end{tabular}

Fonte: Autores.

Nas revistas foram considerados para a busca os descritores: Comunicação, Ecossistema Comunicativo, Educomunicação, Mídia-Educação, Tecnologias da Informação e Comunicação (TIC) e suas variáveis: Novas Tecnologias de Informação e Comunicação (NTIC) e Tecnologias Digitais de Informação e Comunicação (TDIC). Conceitos relacionados, tais como, mídia, vídeo, fotografia, cinema, tecnologia e ação comunicativa se mostraram relevantes e pertinentes durante as buscas e também foram considerados. Dessa forma, foram selecionados 116 artigos em um universo de 1.255.

Em um primeiro momento, por meio de leitura cuidadosa dos títulos, resumos e palavras-chave, realizou-se a busca pelos descritores supracitados. Mesmo se tratando de periódicos nacionais, os equivalentes nas versões em inglês e espanhol desses descritores também foram considerados nas buscas.

No segundo momento, foram realizadas novas e cuidadosas leituras dos resumos dos artigos selecionados e a leitura dos textos completos seguida do fichamento de cada um desses artigos dando destaque aos trechos considerados mais importantes, utilizando como critério de identificação, aspectos relacionados ao(s) objetivo(s) do trabalho, as justificativas para seu desenvolvimento, e os modos/meios de interação/participação dos envolvidos. Nestes fichamentos as informações foram separadas da seguinte forma: título do artigo, ano da publicação, nome dos autores, nacionalidade do artigo, formação acadêmica dos autores, palavras-chave, objetivos, principais conclusões e trechos do texto.

Posteriormente, iniciou-se a construção das categorias de análise, por meio da Análise Textual Discursiva (ATD) de acordo com Moraes e Galiazzi (2006). A Análise Textual Discursiva "transita entre duas formas consagradas de análise na pesquisa qualitativa que são a análise de conteúdo e a análise de discurso” (Moraes \& Galiazzi, 2006, p. 118).

Para os autores a ATD é composta por três momentos: desmontagem dos textos (unitarização), estabelecimento de relações (categorização) e captação do novo emergente (meta-textos). A Figura 1 apresenta o passo a passo metodológico da pesquisa, de acordo com a análise textual discursiva. 
Figura 1 - Etapas e desdobramentos da metodologia de Análise Textual Discursiva (ATD) na pesquisa.

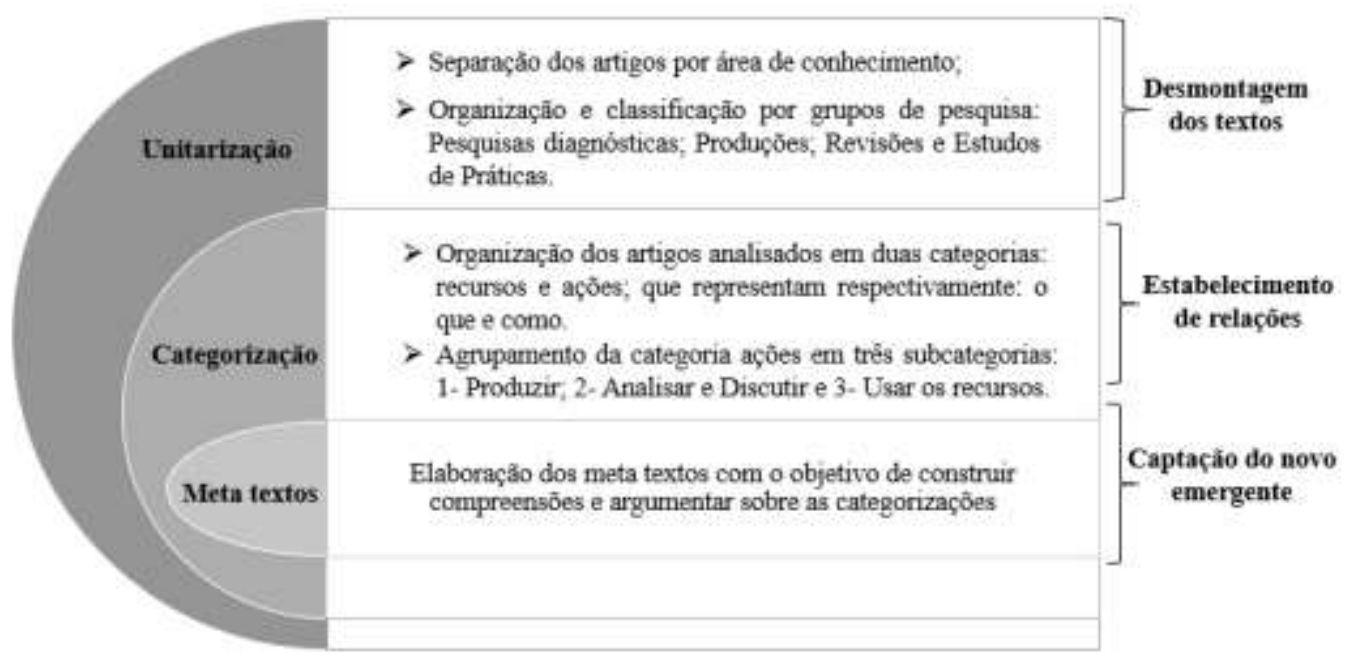

Fonte: Autores.

\section{Resultados}

\section{a. Caracterização geral da presença da comunicação no ensino de ciências}

A análise do conjunto de 116 artigos indicou processos de ensino e aprendizagem em Ciências da Natureza cujas formas de interação se caracterizam pela dinâmica entre o uso e a apropriação tanto dos recursos, quanto das ações de comunicação-educação, bem como por uma grande diversidade de interações e participações entre sujeitos (Tabela 2).

Tabela 2 - Formas de interações comunicativas entre os sujeitos participantes das pesquisas analisadas sobre comunicação no ensino de ciências.

\begin{tabular}{ll}
\hline Participantes & Formas de interação/participação \\
\hline Estudantes & - realizando exercícios nos Ambientes Virtuais de Aprendizagem (AVA), \\
& - assistindo e discutindo vídeos, \\
& - acessando e interagindo em uma WebQuest e Blog, \\
& - observando lâminas em um Microscópio virtual, \\
& - elaborando spots de rádio e conteúdo para um blog, \\
& - estudando e produzindo documentário, e \\
& - participando de oficinas de criação de softwares e construindo softwares \\
& autorais \\
\hline Professores & - produzindo histórias em quadrinhos, \\
& - planejando atividades e criando uma hipermídia com vídeos, textos e \\
& fotografias, \\
& - criando uma FlexQuest, com mini-casos, \\
& - respondendo entrevistas sobre materiais impressos, \\
& - construindo Objeto de Aprendizagem (OA), e \\
& - participando de um processo de formação continuada utilizando o \\
& computador e o Moodle para discutir, realizar tarefas e elaborar materiais \\
& (textos) \\
\hline Outros: comunidade & - compartilhando seus saberes e experiências por meio do diálogo e da \\
de mulheres artesãs; & demonstração, \\
caminhoneiros; & - respondendo entrevistas, lendo e comentando sobre entendimentos acerca \\
profissionais de saúde; $;$ & de materiais impressos educativos, \\
ouvintes de uma & - validando um Objeto de Aprendizagem (OA), e \\
rádio-web & - ouvindo um programa educativo e interagindo via mensagens no MSN. \\
\hline
\end{tabular}

Fonte: Elaborada pelos autores com dados da pesquisa. 
Aliado a essas formas de interação, os objetivos dos trabalhos analisados permitem perceber como, no contexto do Ensino de Ciências da Natureza, a comunicação foi desenvolvida, bem como perceber a maneira como a área tem se apropriado, discutido e apresentado os diferentes meios e formas de comunicação, que foram classificados em três categorias: A) serem preponderantemente descritivos quando, por exemplo, tiveram por objetivo mostrar como a fotografia pode instrumentalizar a Educação Ambiental (Borges et al, 2010); B) terem aplicação prática no ensino quando utilizaram o software ChemSketch ${ }^{\circledR}$ versão 12.1 da empresa ACD/Labs (ACD Chemsketch, 2012) como alternativa didática para a representação e estudos de estruturas moleculares tridimensionais (Silva et al, 2017), e quando duas professoras desenvolveram um estudo dirigido para ser utilizado por estudantes que possuíam dispositivos móveis, tais como tablets, celulares, smartphones, laptops, entre outros (Jacon et al 2014); e C) terem um enfoque mais democrático e proporcionar protagonismo quando professoras solicitaram que seus estudantes elaborassem folders informativos relacionados às questões ambientais, concedendo-lhes liberdade criativa e expressão das necessidades perceptíveis por eles na comunidade em que viviam (Wollmann \& Braibante, 2014).

No que diz respeito aos recursos explorados nas pesquisas analisadas foi identificada uma grande variedade que contempla a linguagem oral, "primeira forma organizada de comunicação humana" (Bordenave, 2017, p. 25), os meios tradicionais (tais como rádio, televisão, imprensa escrita) e os meios digitais. Todos eles podem ser entendidos como tecnologias elaboradas e utilizadas pelos seres humanos nos processos comunicacionais que estabelecem. Na Tabela 3 é possível visualizar a diversidade de recursos empregados pelos autores para desenvolverem suas pesquisas e propostas de trabalhos.

Tabela 3 - Tipos de recursos explorados pelos autores e suas ocorrências nas pesquisas.

\begin{tabular}{lcc}
\hline \multicolumn{1}{c}{ Recursos } & $\begin{array}{c}\text { Frequência de } \\
\text { ocorrência }\end{array}$ & $\%$ \\
\hline Plataformas, softwares e aplicativos & 43 & 40,2 \\
Audiovisuais & 17 & 15,9 \\
Materiais impressos & 16 & 14,9 \\
Linguagens $^{2}$ & 15 & 14,2 \\
Multimídias & 7 & 6,5 \\
Fotografia & 3 & 2,8 \\
Rádio & 2 & 1,9 \\
Música & 1 & 0,9 \\
Vídeo Game & 1 & 0,9 \\
Geotecnologias & 1 & 0,9 \\
Calorímetro & 1 & 0,9 \\
\hline
\end{tabular}

Fonte: Elaborada pelos autores com dados da pesquisa.

Dentre os recursos que tem mais destaque estão o computador e a internet pelas associações e desenvolvimento de atividades que possibilitam. Isso fica explícito quando se observa na tabela a prevalência dos meios digitais que contemplam:

- Plataformas, Softwares e Aplicativos $\Rightarrow$ Ambientes Virtuais de Aprendizagem (AVA) como Chats, Fóruns de discussão, Moodle e os Massive Open Online Courses (MOOC); o computador em si; os softwares; os simuladores computacionais; um microscópio virtual; as WebQuest; os blogs; os Objetos de Aprendizagem (OA) disponíveis online; um banco de dados em um site; as mídias sociais como Facebook e Orkut e os dispositivos móveis Smartphones e Tablets;

- Audiovisuais => curta de animação; documentários, filmes, programas de TV, telejornais e vídeos;

- Multimídias => Compact Disc (CD) e suas variações como os Blu-Ray, CD-ROM e o DVD, uma TV pendrive ou TV multimídia e um micro portal multimídia.

\footnotetext{
${ }^{2}$ A linguagem, por ser entendida neste trabalho como um tipo de tecnologia, é considerada como recurso.
} 
Há ainda materiais impressos como cartazes, cartilhas, folders, histórias em quadrinhos, jornal impresso, revistas e textos de divulgação científica. E a linguagem que, com toda sua relevância nas formas oral e escrita, contemplam os discursos, os conteúdos relativos à participação em entrevistas e questionários, as conversas online que correspondem as interações nos blogs, chats e fórum, os gestos e a postura corporal do professor.

Essa diversidade de recursos constitui uma grande teia de relações que se estabelecem nos entrecruzamentos entre eles, dentre os quais destacam-se os meios digitais ou Novas Tecnologias de Informação e Comunicação (NTIC), entendidas, segundo Carvalho (2009), como: TV, fotografia, vídeo, cinema e som digitais, bem como computadores, internet, webcams, pen drives, cartões de memória, celulares e outras infinidades tecnológicas.

Ainda em relações aos recursos, os meios digitais de comunicação são considerados importantes pelos autores a partir de várias justificativas com destaque para: a) despertar o interesse dos estudantes (Alves \& Messeder, 2011; Andrade Júnior et al, 2010; Xavier et al, 2010); b) facilitar o processo de ensino e aprendizagem (Bulegon \& Tarouco, 2015; Fraiha-Martins \& Gonçalves, 2012; Gonzales \& Rosa, 2014; Ruiz-moreno et al, 2013); c) valorizar as práticas pedagógicas (Gabini \& Diniz, 2012; Araújo; et al, 2017); d) possibilitar uma outra dinâmica em sala de aula (na medida em que agrega ações conjuntas) (Andrade et al, 2017; Silva \& Carvalho, 2014); e) como forma de tornar mais atrativo o ensino de conceitos científicos (Almeida et al, 2015; Biazus \& Rosa, 2016); e f) possibilitar percepções que seriam complicadas ou até mesmo impossíveis sem seu uso, tornando visíveis alguns processos das ciências que ficam no nível da abstração (Gregório et al, 2016; Schnorr et al, 2017).

\section{b. Comunicação como processo ou produto?}

As ações se desdobram em processos cujas finalidades, sujeitos, interações, recursos e metodologias variaram dentro do contexto do Ensino de Ciências e contemplaram três subcategorias, (i) Produzir; (ii) Analisar e Discutir; e (iii) Usar os recursos, nas quais: (i) Produzir é uma ação que revela protagonistas, o potencial criativo e as possibilidades decorrentes da elaboração de produtos de comunicação a partir de recursos diversos; (ii) Analisar e Discutir são duas ações que dizem respeito a avaliação dos diferentes meios de expressão e comunicação permitindo refletir sobre a abrangência da comunicação nos processos de ensino e aprendizagem; e (iii) Usar os recursos é uma ação que explicita a diversidade de recursos que podem ser empregados nos processos comunicativos, bem como as diferentes formas de participação e interações que se estabelecem em seus usos, com foco na perspectiva do sujeito enquanto usuário do produto ou do meio, e não como produtor.

Em relação às produções destacaram-se como protagonistas os pesquisadores, denominação que foi dada aos autores das pesquisas que não foram identificados como professores da educação básica ou superior, seguido dos estudantes de graduação e de um número reduzido de professores (da educação básica) e estudantes, totalizando trinta e quatro produtores (Figura 2). 
Figura 2. Perfis dos sujeitos autores dos produtos de comunicação apresentados nos artigos pesquisados

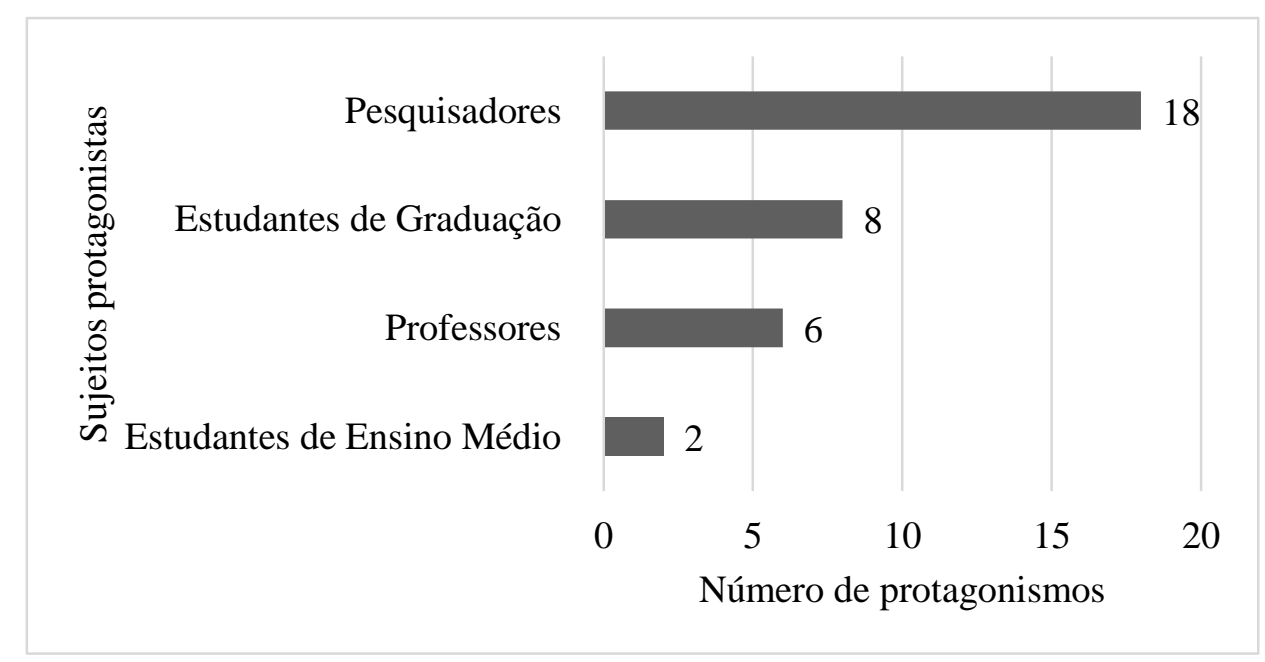

Fonte: Elaborada pelos autores com dados da pesquisa.

A subcategoria analisar e discutir foi desmembrada de acordo com os recursos que foram analisados e discutidos pelos pesquisadores resultando em sete tipos que correspondem aos itens destacados na Tabela 4:

Tabela 4 - Tipos e ocorrência de recursos analisados e discutidos.

\begin{tabular}{lcc}
\hline \multicolumn{1}{c}{ Recursos analisados e discutidos } & $\mathbf{N}^{\circ}$ de análises e discussões & \% \\
\hline Linguagem & 17 & 32,7 \\
Mídia impressa & 12 & 23,1 \\
Audiovisual & 9 & 17,3 \\
Plataformas, Softwares e Aplicativos & 7 & 13,5 \\
Mídia eletrônica & 4 & 7,7 \\
Cursos e propostas de ensino & 2 & 3,8 \\
Tecnologia Assistiva $^{3}$ & 1 & 1,9 \\
\hline
\end{tabular}

Fonte: Elaborada pelos autores com dados da pesquisa.

As classificações mídia eletrônica e mídia impressa integraram juntas dezesseis tipos de mídias, ou seja, 30,8\% do total de recursos analisados e discutidos, demonstrando a prevalência de análises e discussões de conteúdos vinculados em diferentes mídias.

Já o uso dos recursos foi se revelando por meio de ações que tiveram como foco principal processos de ensino e aprendizagem em Ciências. Usar os recursos implica entrar em contato, interagir, contudo sem envolver a produção de conteúdo de comunicação. A Tabela 5 mostra os diferentes recursos que foram utilizados.

\footnotetext{
${ }^{3}$ As tecnologias assistivas correspondem a materiais adaptados para estudantes com deficiência. Nesse caso específico, trata-se de materiais de polipropileno adaptados para estudantes com deficiência visual.
} 
Tabela 5 - Variedade de recursos e frequência de usos.

\begin{tabular}{lcc}
\hline \multicolumn{1}{c}{ Recursos utilizados } & Frequência de uso & \% \\
\hline Plataformas, Softwares e Aplicativos & 30 & 52,6 \\
Audiovisual & 9 & 15,8 \\
Materiais impressos & 6 & 10,6 \\
Multimídias & 5 & 8,9 \\
Jogos & 2 & 3,6 \\
Tecnologia Assistiva & 1 & 1,7 \\
Programa de rádio & 1 & 1,7 \\
Geotecnologia & 1 & 1,7 \\
Fotografia & 1 & 1,7 \\
Cursos e propostas de ensino & 1 & 1,7 \\
\hline
\end{tabular}

Fonte: Elaborada pelos autores com dados da pesquisa.

Dessa forma, nessa subcategoria, é possível perceber uma variedade de recursos usados na comunicação para e por um público diverso dentro do universo da Educação em Ciências da Natureza.

\section{Discussão}

Nos trabalhos analisados, linguagem oral, gestual, corporal, meios tradicionais e meios digitais de comunicação convivem e são resultado de relações e interações em processos de ensino e aprendizagem em Ciências da Natureza desenvolvidos por pesquisadores, educadores e educandos, dentro ou fora da sala de aula.

Nesse sentido, um primeiro aspecto a ser mencionado se refere aos recursos e seus usos, pois é preciso dar sentido aos usos e aliar a eles elementos como trabalho coletivo, diálogos e discussões, propiciando momentos de livre expressão e democratização desses recursos por meio do acesso fácil e gratuito, e um planejamento consciente por parte do proponente da ação, seja nos espaços de educação formal ou não-formal. Em consonância com essa ideia, Martín-Barbero (2000, p. 52) defende que "nada pode prejudicar mais a educação do que nela introduzir modernizações tecnológicas sem antes mudar o modelo de comunicação que está por debaixo do sistema escolar”.

Dessa forma, é importante destacar o papel do professor nos processos de comunicação e uso de tecnologias, pois o professor de Ciências da Natureza, ao propor atividades envolvendo tecnologias, deve ter a consciência de que os meios tradicionais e os digitais por si só não garantem processos de ensino e aprendizagem. É preciso planejamento, organização e cautela para não evidenciar os recursos em detrimento das ideias criativas que integram, ou pelo menos deveriam integrar, o planejamento das aulas.

Trata-se de assistir o vídeo e entender por que o assistiu, usar um software e interagir dinâmica e criticamente com ele, produzir materiais, propor e analisar práticas na forma de problemas de pesquisa e investigação, pois para que o ensino de Ciências seja desafiador, é preciso haver uma postura curiosa e investigativa, envolvimento dos sujeitos e protagonismo. O conhecimento científico implica diálogos e problematização, pois assim como afirma Freire (2015, p. 68), “[...] nenhum pensador, como nenhum cientista, elaborou seu pensamento ou sistematizou seu saber científico sem ter sido problematizado, desafiado".

O diálogo e a problematização não adormecem a ninguém. Conscientizam. Na dialogicidade, na problematização, educador-educando e educando-educador vão ambos desenvolvendo uma postura crítica da qual resulta a percepção de que este conjunto de saber se encontra em interação. (Freire, 2015, p. 70)

Nesse sentido, uma importante compreensão é a ideia de que nos processos de ensino e aprendizagem, as NTIC, aqui caracterizadas como os meios digitais, não podem ser interpretadas ou usadas como inovações, contudo elas devem 
acompanhar inovações que devem partir das ideias e propostas de quem pensa e planeja os processos de ensino e aprendizagem. Assim, elas devem ser compreendidas como parte, como recurso auxiliar para promover processos de formação crítico-cidadã que gerem envolvimento coletivo, protagonismo, autonomia, leitura crítica, livre expressão e democratização dos meios.

Para Machado (2016, p. 53), em Freire "todo processo de autonomia e de construção de consciência nos sujeitos exige uma reflexão crítica e prática, de modo que o próprio discurso teórico terá de ser alinhado à sua aplicação". Compreendemos, dessa forma, que o protagonismo que conscientiza é capaz de gerar, também, autonomia, e que a comunicação, por meio dos recursos que tem disponível e que vão desde a linguagem até os aparatos mais sofisticados, pode possibilitar, através do incentivo à criatividade, o protagonismo e a autonomia nos processos de ensino e aprendizagem.

Dessa forma, um segundo aspecto que merece destaque, e que também tem relação com os recursos e nos permite discutir sobre protagonismo e autonomia, diz respeito à subcategoria produzir, referente à categoria ação, pois as produções ainda estão concentradas no Ensino Superior, ou seja, nos cursos de formação e nas ações de pesquisadores. Os dados mostram que juntos estudantes do Ensino Médio (6\%) e de Graduação (24\%) representam apenas 30\% do total de produções realizadas, o que é um número reduzido em comparação a professores (17\%) e pesquisadores (53\%) que juntos somam 70\% do total de todas as produções.

Esses dados são relevantes, pois juntos revelam o desenvolvimento e a elaboração dos recursos, possibilitando a dimensão das formas de participação e interação dos sujeitos envolvidos no processo de pesquisa. Também evidenciam que são necessários movimentos que estimulem o protagonismo e a ação por parte dos estudantes, pois assim como afirma Mário Kaplún (2014, p.78) "os receptores se tornam mais autônomos à medida que eles mesmos exercem e praticam o ato emissor". Para o autor,

A apropriação do conhecimento pelos alunos se catalisa quando eles são instituídos e potencializados como emissores. Seu processo de aprendizagem é favorecido e incrementado pela realização de produtos comunicáveis e efetivamente comunicados. (Kaplún, 2014, p. 78)

No que concerne à questão da produção e do protagonismo, Freire (2011) afirma que "a prática do fazer, de criar, de pensar, de projetar um material, que corresponda às condições concretas, sociais, da população de uma área, é uma prática profundamente pedagógica" (Freire, 2011, p. 131). De acordo com ele, o estudante deve ser prioritariamente sujeito da sua própria formação (Freire \& Guimarães, 2011).

Um ambiente de ensino e aprendizagem em que estudantes, professores e comunidade participam coletivamente protagonizando processos de ensino e aprendizagem dificulta o "ato depositário" de informações e conceitos tão criticado onde "em vez de comunicar, o professor dá comunicados e faz colocações que os alunos recebem passivamente, aprendem e repetem" (Freire, 2018, p.131), pois ao protagonizar processos de ensino e aprendizagem orientados e estimulados por seus professores, os estudantes podem envolver-se em um importante processo educativo-comunicativo.

No que concerne as contexturas estabelecidas entre educação, comunicação, diálogos e participação, Martín-Barbero (2014, p. 78) afirma que:

Se comunicar é compartilhar a significação, participar é compartilhar a ação. A educação seria, então, o lugar decisivo de seu entrecruzamento. Mas para isso deverá se converter no espaço de conversação dos saberes e narrativas que configuram as oralidades, as literalidades e as visualidades. Pois das mestiçagens que entre elas se tramam é de onde se vislumbra e se expressa, ganha corpo o futuro. 
Dessa forma, as ações educativas e comunicativas devem estar dispostas a mobilizar, promover e ampliar espaços de diálogo, pois só assim cumprirão o seu papel sociopolítico de formação cidadã e promoção da inclusão por meio do incentivo à participação social coletiva. Compreende-se que isso só será possível quando todos puderem participar protagonizando, em diferentes níveis e dentro das possibilidades, os processos educativos-comunicativos que acontecem nos espaços de educação e da comunicação.

Integrando os processos de ensino e aprendizagem, as mídias impressas e as audiovisuais estiveram presentes nos artigos analisados e seus formatos variaram entre textos de jornais e revista, panfletos, cartazes, história em quadrinhos, vídeos, documentários, telejornais, programas de TV dentre outros. No que concerne à sua inserção nos processos de ensino e aprendizagem, as mídias

Propiciam momentos de interação entre os participantes, fornecendo novos mecanismos de percepção, análise e interpretação para as temáticas desenvolvidas em aula. Valorizam os encontros, ao aproximar o aluno de realidades com as quais dificilmente entrariam em contato se não fosse por esse meio. Dessa forma, é importante um planejamento didático que insira esse recurso na prática pedagógica, ampliando as possibilidades de informação, debate e compreensão do cotidiano midiático. (Koeppe et al, 2013, p.25)

Por se tratarem de importantes vias comunicativas entre quem produz a ciência e a população leiga, estes recursos nos remetem a pensar o processo de divulgação das ciências e sua relação com a escola e a sala de aula. Permitem refletir que, com o desenvolvimento tecnológico, esses recursos têm chegado cada vez mais e de diferentes formas, com acessos rápidos e fáceis, integrando a gama de informações disponíveis. Contudo, a presença das temáticas e conceitos científicos na mídia exigem dos processos educativos em Ciências o trabalho de discussão e percepção crítica dos diversos meios e veículos de informação, pois, assim como afirmam, Gomes et al (2020, p.2), "a circulação de discursos não é de exclusividade da mídia jornalística ou dos meios oficiais de divulgação científica",

Hoje, os próprios usuários das redes sociais 'curtem' as mais diversas informações e compartilham-nas com os mais diversos públicos. Essa talvez fosse uma grande oportunidade de democratização da informação, entretanto esse território virtual se manifesta repleto de disputas discursivas entre o real e a ficção. (Gomes et al 2020, p.2)

De fato, os caminhos da divulgação científica "passam pelos estreitos vales traçados pelos meios de comunicação globais e seus mercadores" (Candotti, 2002, p. 16), sofrem influências diversas e estão suscetíveis a manipulações de usuários cada vez mais dinâmicos dentro das mídias sociais. Dessa forma, assim como são variadas a formas de acesso também são as intencionalidades que influenciam não só a leitura, mas o compartilhamento, produção e transformação dos conteúdos que estão acessíveis nesse território virtual que tem sido amplamente explorado. Nesse sentido, como uma das formas que nossos estudantes têm de interagir com as Ciências, os materiais de divulgação científica devem ser empreendidos como recursos potencializadores de discussões em sala de aula.

De acordo com Porto (1998, p. 24), “o homem, como ser de relações (não só com os pares, mas com as situações, as informações, os objetivos), vive processos de reciprocidade, de comunicação". Em uma dinâmica em que os formatos impresso, eletrônico e audiovisual se misturam e se complementam, os sujeitos estão em constante diálogo com as mídias e isso exige reflexão e leitura crítica. Exige comunicação e problematização, pois para Freire (2015, p. 110) a problematização se dá na comunicação "em torno das situações reais, concretas, existenciais, ou em torno dos conteúdos intelectuais referidos também ao concreto". Para o autor não existe problematização sem comunicação, diálogo e sujeitos comprometidos e não é possível problematizar sem envolver-se, pois, "a problematização implica um retorno crítico a ação" (Freire, 2015, p. 111).

Para Martín-Barbero (2000, p. 53), "falar em comunicação significa, em primeiro lugar, reconhecer que estamos em uma sociedade em que o conhecimento e a informação têm um papel fundamental". Mais do que nunca se faz necessária uma 
comunicação que ensine a questionar, a refletir, se posicionar criticamente, argumentar, e que dê aos estudantes condições de pensar sobre e participar das decisões decorrentes das relações e interações do mundo que os cerca.

Em uma outra perspectiva, nos trabalhos da subcategoria "Analisar e Discutir" prevalecem as análises e discussões sobre linguagens (discursos, narrativas, conteúdos). Essas análises e discussões são importantes do ponto de vista da interface educação-comunicação por permitirem uma visão da comunicação para além dos meios tradicionais e digitais quando, por exemplo, buscam compreender as principais barreiras para inclusão de estudantes com deficiência visual, ou quando analisam os discursos e as narrativas em sala de aula. São pesquisas que permitem pensar a comunicação como ação de compartilhamento de mensagens e a linguagem como meio de comunicação, sendo esta entendida como base da comunicação em sala de aula e dos processos de ensino e aprendizagem e que nos trazem a compreensão de que

As relações dialógicas são relações sociais de valor, entendidas como uma complexa rede estruturada entre enunciados e entre sujeitos socialmente organizados e, pois, carregados de sentidos ideológicos e com valores históricos característicos dos sujeitos nela envolvidos. No complexo cenário das relações dialógicas é que se constitui o sujeito e, neste cenário de múltiplas divergências e convergências, o sujeito vai assimilando novas vozes e constituindo suas práticas dialógicas. (Assumpção \& Gouvêa, 2010, p. 57)

Também referentes à subcategoria "analisar e discutir", alguns artigos nos permitem compreender a "comunicação humana como multimodal", ou seja, como um processo em que coexistem mais de uma modalidade de comunicação, e os conceitos científicos como "híbridos semióticos", que se constituem como a mistura de signos e simbologias. Essa é uma compreensão essencial para o professor e sua atuação em sala, pois a partir dessa consciência os planejamentos e as ações podem propiciar maior envolvimento e desempenho dos estudantes participantes nos processos de ensino e aprendizagem.

No contexto da educação escolar, a escolha e a combinação dos modos de comunicação são essenciais para que o professor possa promover o entendimento de conceitos e permitir a apropriação ou o domínio de aspectos da cultura das ciências pelos estudantes. (Cappelle \& Paula, 2016, p. 695)

Os trabalhos sobre multimodalidade do discurso e da comunicação são importantes por nos mostrar a relevância da comunicação em sua complexidade, seus diferentes meios, formas e espaços de acontecer. Remetem tanto à diversidade de discursos, quanto aos recursos e a importância de explorar essa diversificação.

Os artigos que trataram da importância da comunicação como ação de compartilhamento de mensagens, e da linguagem como meio de comunicação para a inclusão e para os processos de ensino e aprendizagem, analisaram discursos e apontaram deficiências nos processos comunicativos em sala de aula. Esses trabalhos sugerem que para alcançar um envolvimento que permita processos de ensino e aprendizagem efetivos são necessárias relações comunicacionais mais integradoras e participativas, e que isso não depende do uso exclusivo de recursos, como os meios tradicionais e digitais, mas de princípios que orientem esses usos.

\section{Considerações Finais}

A comunicação esteve presente em todos os processos educativos descritos por meio de diálogos, escutas, debates, rodas de conversa, trabalhos em grupo, redação de textos, respostas de questionários e de atividades que foram instrumentos de reflexão e avaliação.

Houve a prevalência do uso de recursos digitais como computadores, internet, softwares, Ambientes Virtuais de Aprendizagem (AVA), Objetos de Aprendizagem dentre outros, evidenciando possibilidades e interdependências entre as NTIC e mostrando uma tendência de incorporação de recursos digitais nos processos de ensino e aprendizagem. Essa tendência 
merece ser acompanhada com atenção, observando a necessidade de o educador organizar e planejar tais processos de forma ousada e criativa, na busca pelo protagonismo dos estudantes e da reflexão sobre o uso dos recursos que devem vir acompanhados de leitura crítica e problematização.

No ensino de Ciências, recursos digitais, como os computadores e os softwares, permitem explorar, por meio de representações e simulações virtuais, fenômenos microscópicos e conceitos abstratos necessários na construção do conhecimento científico. Porém, é questionável considerar que o uso de recursos digitais "modernizam" ou "inovam" os processos educativos se associados a reprodução de velhas práticas de ensino, como o exercício da memorização sem contextualização com a realidade. É importante ter clareza de que tão ou mais importantes do que a inserção das tecnologias nas ações pedagógicas, são as concepções de educação, formação e ensino e aprendizagem que dinamizam e integram os usos das NTIC.

De modo geral, a comunicação apareceu nos trabalhos como recurso didático, fornecendo meios para ensinar, mas não como algo a ser discutido com os estudantes ou como competência a ser desenvolvida com eles. A fim de modificar esse cenário, a procura por ações educativo-comunicativas conscientes, e por processos de ensino e aprendizagem em Ciências em que os estudantes sejam protagonistas de suas ações devem ser uma constante integrando o planejamento dos professores.

Nos atuais contextos globais de epidemias, crise ambiental e ataques à legitimidade do conhecimento científico, é essencial fortalecer no ensino de ciência a discussão crítica e dialogada sobre a mídia, incluindo desde os meios de divulgação científica ao jornalismo cotidiano e as redes sociais, possibilitando a reflexão racional que separe o conhecimento confiável de uma crescente proliferação de notícias falsas.

O mapeamento e os resultados de análise realizados nessa pesquisa contribuem para ampliar o conhecimento sobre a comunicação no ensino de Ciências na medida em que apresenta possibilidades de produção, análise, discussão e utilização de recursos e interações comunicativas presentes em processos de ensino e aprendizagem em Ciências. Espera-se com esse artigo proporcionar reflexões e compreensões que se desdobrem em ações didáticas mais críticas e conscientes pelos educadores em Ciências.

\section{Agradecimentos}

O presente trabalho foi realizado com apoio da Coordenação de Aperfeiçoamento de Pessoal de Nível Superior Brasil (CAPES).

\section{Referências}

Adorno, G., \& Silveira, J. (2018). Pós-verdade e fake news: equívocos do político na materialidade digital. In: Seminário de estudos em análise do discurso (sead): o político na análise do discurso: contradição, silenciamento e resistência. Anais do $8^{\circ}$ SEAD.

Almeida, C. M. M., Costa, R. D. A., \& Lopes, P. T. C. (2015). Prática educativa e aprendizagem significativa: utilizando uma sequência didática eletrônica na plataforma SIENA. Experiências em Ensino de Ciências, 10 (3), 31-39.

Alves, E. M., \& Messeder, J. C. (2011). Produção de um recurso audiovisual com enfoque CTS como instrumento facilitador do ensino experimental de ciências. Experiências em Ensino de Ciências, Cuiabá, 6 (3),100-117.

Andrade, D. X., Genovese, C. L. C. R, \& Genovese, L. G. R. (2017). A controvérsia entre o Blu-ray e o HD-DVD em aulas de física na perspectiva da social construction of technology (SCOT). Experiências em Ensino de Ciências, 12 (2), 1-23.

Andrade-junior, J. A., Dantas, C. R. S., \& Nobre, F. A. S. (2010). O estudo de energia: uma experiência de ensino na perspectiva CTS e o uso de mídias. Experiências em ensino de ciências, 5 (1), 21-29.

Araujo, C. B., Santos, R. F., \& Giannella, T. R. (2017). Saúde e cidadania: os sentidos do corpo: análise de uma atividade educativa mediada pelas tecnologias digitais de informação e comunicação. Experiências em Ensino de Ciências, 12 (3), 56-68.

Assumpção, A., \& Gouvêa, G. (2010). Práticas enunciativas em um evento de divulgação científica em um museu de ciências do Rio de Janeiro. Ensaio Pesquisa em Educação em Ciências, 12 (2), 49-68.

Bazzo, W. A. (2012). Cultura científica versus humanística: a CTS é o elo? Revista Iberoamericana de Educación, 58 (3), $61-79$. 
Belloni, M. L. (2009). O que é mídia-educação. Campinas: Autores Associados.

BernardazzI, R. (2016). Youtubers e as relações com a produção audiovisual. In Anais do XXXIX Congresso Brasileiro de Ciências da Comunicação (Intercom), São Paulo.

Biazus, M. O., \& Rosa, C. W. (2016). Abordagem de tópicos de mecânica quântica no ensino médio partindo da aproximação com o cotidiano. Experiências em Ensino de Ciências, 11 (3), 59-177.

Bordenave, J. D. (2017). O que é comunicação. Brasiliense.

Borges, M. D, Aranha, J. M., \& Sabino, J. (2010). A fotografia de natureza como instrumento para educação ambiental. Ciência \& Educação, 16 (1) 149-161.

Bulegon, A. M., \& Tarouco, L. M. R. (2015). Contribuições dos objetos de aprendizagem para ensejar o desenvolvimento do pensamento crítico nos estudantes nas aulas de Física. Ciência \& Educação, 21 (3), 743-763.

Praia, J., \& Jorge, M. (2000). Ciência, educação em ciência e ensino das ciências. Lisboa: Ministério da Educação.

Candotti, E. (2002). Ciência na Educação Popular. In: Brito, F., Massarani, L, Moreira, I. C. (Orgs.). Ciência e público: caminhos da divulgação científica no Brasil. Rio de Janeiro: Casa da Ciência/UFRJ.

Cappelle, V., \& Paula, H. F. (2016). Interação com imagens e gesticulação em uma aula de Biologia. Revista Brasileira de Pesquisa em Educação em Ciências, $16(3), 693-723$.

Carvalho, V. (2009). O que são NTICs? http://linguagemmultimidia.blogspot.com/.

Chassot, A. (2000). Alfabetização científica: questões e desafios para a educação. Ijuí: Editora Unijuí.

Citelli, A. O., \& Costa, M. C. C. (2011). Educomunicação: construindo uma nova área de conhecimento. Paulinas.

Freire, P. (2011). Pedagogia dos Sonhos Possíveis. Ana Maria Araújo Freire (org.).: Editora Paz e Terra.

Freire, P., \& Guimarães, S. (2011). Educar com a mídia: novos diálogos sobre educação. Paz e Terra.

Freire, P. (2015). Extensão ou comunicação? Editora Paz e Terra.

Freire, P. (2018). Conscientização. Cortez Editora.

Fraiha-Martins, F., \& Gonçalves, T. V. O. (2012). Informática na educação matemática e científica dos anos iniciais de escolaridade: um estudo sobre as pesquisas da área ensino de Ciências e Matemática. Ensaio Pesquisa em Educação em Ciências,14 (3), $313-331$.

Gabini, Wanderlei Sebastião, Diniz, Renato Eugênio da Silva. (2012). A formação continuada, o uso do computador e as aulas de ciências nos anos iniciais do ensino fundamental. Ensaio Pesquisa em Educação em Ciências, 14 (3),333-348.

Gomes, S. F., Penna, J. C. B. D. O., \& Arroio, A. (2020). Fake news científicas: percepção, persuasão e letramento. Ciência \& Educação (Bauru), 26.

Gonzales, E. G., \& da Silva Rosa, P. R. (2016). Aprendizagem significativa de conceitos de circuitos elétricos utilizando um ambiente virtual de ensino por alunos da Educação de Jovens e Adultos. Investigações em Ensino de Ciências, 19(2), 477-504.

Gregório, E. A., de Oliveira, L. G., \& de Matos, S. A. (2016). Uso de simuladores como ferramenta no ensino de conceitos abstratos de Biologia: uma proposição investigativa para o ensino de síntese proteica. Experiências em ensino de Ciências, 11(1), 101-125.

Henriques, C. M. P. (2018). A dupla epidemia: febre amarela e desinformação. Revista Eletrônica de Comunicação, Informação e Inovação em Saúde, 12(1).

Jacon, L. D. S. C., de Oliveira, A. C. G., de Moraes Marti, E. A. L., \& de Mello, I. C. (2016). Os formadores de professores e o desafio em potencializar o ensino de conhecimentos químicos com a incorporação dos dispositivos móveis. Investigações em Ensino de Ciências, 19(1), 77-89.

Kaplún, M. (1999). Processos educativos e canais de comunicação. Comunicação \& Educação, 14 (1) 68-75.

Kaplún, M. (2014). Uma pedagogia da comunicação. In Aparici, Roberto (org.) Educomunicação: para além do 2.0. Paulinas.

Koeppe, C. H. B., Lahm, R. A., \& Borges, R. M. R. (2013). Usina hidrelétrica de Belo Monte: uma polêmica atual para despertar a educação ambiental crítica. Experiências em Ensino de Ciências, 8 (1), 17-28.

Leher, R. (2019). Autoritarismo contra a universidade: o desafio de popularizar a defesa da educação pública. São Paulo: Fundação Rosa Luxemburgo, Expressão Popular.

Machado, R. C. F. (2016). Autonomia. In: Streck, Danilo, Redin, Euclides, Zitkoski, Jaime José (orgs.). Dicionário Paulo Freire, Belo Horizonte: Autentica Editora.

Martín-Barbero, J. (2000). Desafios culturais da comunicação à educação. Comunicação \& Educação, 18 (1), 51 -61.

Martín-Barbero, J. (2014). A comunicação na Educação. Contexto.

Monari, A. C. P., \& Bertolli Filho, C. (2019). Saúde sem Fake News: estudo e caracterização das informações falsas divulgadas no Canal de Informação e Checagem de Fake News do Ministério da Saúde. Revista Mídia e Cotidiano, 13 (1), 160-186. 
Research, Society and Development, v. 10, n. 16, e273101623430, 2021

(CC BY 4.0) | ISSN 2525-3409 | DOI: http://dx.doi.org/10.33448/rsd-v10i16.23430

Moraes, R., \& Galiazzi, M. C. (2006). Análise textual discursiva: processo reconstrutivo de múltiplas faces. Ciência \& Educação, 12, (1), 117-128.

Oliveira, S. M. P. (2018). Disseminação da informação na era das fake news. Múltiplos Olhares em Ciência da Informação, 8 (2), $1-15$.

Porto, T. M. E. (1998). Educação para a mídia/pedagogia da comunicação: caminhos e desafios. Pedagogia da comunicação: teorias e práticas. São Paulo: Cortez, 23-49.

Ribeiro, B. C. M. D. S., Franco, I. D. M., \& Soares, C. C. (2018). Competência em Informação: as fake news no contexto da vacinação. Belo Horizonte, 8 (2), $1-5$.

Ruiz-Moreno, L., Leite, M. T. M., \& Ajzen, C. (2013). Formação didático-pedagógica em saúde: habilidades cognitivas desenvolvidas pelos pós-graduandos no ambiente virtual de aprendizagem. Ciência \& Educação (Bauru), 19, 217-229.

Saad, E., \& Raposo, J. F. (2017). Prosumers: colaboradores, cocriadores e influenciadores. Revista Communicare, São Paulo, 17(1), 114-130.

Santos, W. L. P. (2008). Educação científica humanística em uma perspectiva freireana: resgatando a função do ensino de CTS. Alexandria: revista de educação em ciência e tecnologia, 1(1), 109-131.

Santos, W. L. P. (2012). Educação CTS e cidadania: confluências e diferenças. Amazônia: Revista de educação em ciências e matemáticas, 9(17), 49-62.

Santos, W. L. P., \& Mortimer, E. F. (2009). Abordagem de aspectos sociocientíficos em aulas de ciências: possibilidades e limitações. Investigações em ensino de Ciências, 14(2), 191-218.

Simão, A. M. V., \& de Souza, S. B. (2017). Cyberbullying: incidência, consequências e contributos para o diagnóstico no ensino superior. Revista@ mbienteeducação, 7(1), 90-104.

Souza, S. B., Simão, A. M. V., \& Caetano, A. P. (2014). Cyberbullying: percepções acerca do fenômeno e das estratégias de enfrentamento. Psicologia: Reflexão e Crítica, 27, 582-590.

Schnorr, S. M., Rodrigues, C. G., \& Islas, C. A. (2017). O uso das tecnologias contemporâneas como recurso pedagógico para as aulas de Ciências. Experiências em Ensino de Ciências, 12(3), 31-42.

Silva, C. S., de Souza Júnior, E. V., \& Pires, D. A. T. (2017). O uso de software de representação molecular em 3D como material didático interdisciplinar para o Ensino de Química. Experiências em Ensino de Ciências, 12(2), 66-79.

Silva, J. R. N., \& de Carvalho, L. M. O. (2016). Uma compreensão do processo de interação comunicativa em grupos de planejamento conjunto entre docentes da licenciatura em física na perspectiva da teoria do agir comunicativo. Investigações em Ensino de Ciências, 21 (1), $145-165$.

Teixeira, A. (2018). Fake news contra a vida: desinformação ameaça vacinação de combate à febre amarela.

Teixeira, P. M. M. (2003). A educação científica sob a perspectiva da pedagogia histórico-crítica e do movimento CTS no ensino de ciências. Ciência \& Educação (Bauru), 9(2), 177-190.

Xavier, C. H. G., Passos, C. M. B., Freire, P. D. T. C., \& de Araújo Coelho, A. (2010). O uso do Cinema para o ensino de física no ensino médio. Experiências em ensino de ciências, 5(2), 91-105.

Wollmann, E. M., \& Braibante, M. E. F. (2014). Utilizando a elaboração de folders para a construção da cidadania com estudantes do Ensino Médio. Revista Brasileira de Pesquisa em Educação em Ciências, 14(2), 265-278. 